OPEN ACCESS

Edited by:

Xiaogang $W u$,

Institute for Systems Biology,

United States

Reviewed by:

Anatoly Sorokin,

Institute of Cell Biophysics (RAS),

Russia

Nicola Bernabò,

Università di Teramo, Italy

*Correspondence:

Gyuhwa Chung

chung@chonnam.ac.kr

Seung $H$. Yang

ymichigan@jnu.ac.kr

Zahid Hussain Shah

shahzahid578@hotmail.com

Specialty section:

This article was submitted to

Systems Biology,

a section of the journal

Frontiers in Genetics

Received: 07 July 2017

Accepted: 21 September 2017

Published: 17 October 2017

Citation:

Shah ZH, Rehman HM, Akhtar T,

Daur I, Nawaz MA, Ahmad MQ,

Rana IA, Atif RM, Yang SH and

Chung G (2017) Redox and lonic

Homeostasis Regulations against Oxidative, Salinity and Drought Stress

in Wheat (A Systems Biology Approach). Front. Genet. 8:141. doi: 10.3389/fgene.2017.00141

\section{Redox and lonic Homeostasis Regulations against Oxidative, Salinity and Drought Stress in Wheat (A Systems Biology Approach)}

\author{
Zahid Hussain Shah' ${ }^{*}$, Hafiz M. Rehman², Tasneem Akhtar ${ }^{1}$, Ihsanullah Daur', \\ Muhammad A. Nawaz' ${ }^{2}$ Muhammad Q. Ahmad ${ }^{3}$, Iqrar A. Rana ${ }^{4}$, Rana M. Atif ${ }^{4,5}$, \\ Seung H. Yang ${ }^{2 *}$ and Gyuhwa Chung ${ }^{2 *}$
}

\begin{abstract}
1 Department of Arid Land Agriculture, King Abdulaziz University, Jeddah, Saudi Arabia, ${ }^{2}$ Department of Electronics and Biomedical Engineering, Chonnam National University, Yeosu, South Korea, ${ }^{3}$ Department of Plant Breeding and Genetics, Bahauddin Zakariya University, Multan, Pakistan, ${ }^{4}$ Centre of Agricultural Biochemistry and Biotechnology (CABB), University of Agriculture Faisalabad, Faisalabad, Pakistan, ${ }^{5}$ Department of Plant Breeding and Genetics, University of Agriculture Faisalabad, Faisalabad, Pakistan
\end{abstract}

Systems biology and omics has provided a comprehensive understanding about the dynamics of the genome, metabolome, transcriptome, and proteome under stress. In wheat, abiotic stresses trigger specific networks of pathways involved in redox and ionic homeostasis as well as osmotic balance. These networks are considerably more complicated than those in model plants, and therefore, counter models are proposed by unifying the approaches of omics and stress systems biology. Furthermore, crosstalk among these pathways is monitored by the regulation and streaming of transcripts and genes. In this review, we discuss systems biology and omics as a promising tool to study responses to oxidative, salinity, and drought stress in wheat.

Keywords: wheat, salinity, drought, oxidative, redox

\section{INTRODUCTION}

Bread wheat (Triticum aestivum L.) is cultivated globally on 200 million ha, with a production of 650 million tons per annum, ranking third after maize and rice (Akpinar et al., 2015). Bread wheat fulfills $20 \%$ of the human dietary energy requirement, and is therefore considered a vital component of human diet (Kurtoglu et al., 2014). About $82-85 \%$ of the global population depends on wheat for basic food ingredients, i.e., protein, dietary fiber, vitamins, phytochemicals, sugar, and free amino acids (Akpinar et al., 2015). Steady but sustainable increase in wheat yield is an obligatory requirement for future food security (Mochida and Shinozaki, 2013). Every year, environmental stresses such as drought and salinity cause a substantial loss in crop productivity (Wang et al., 2003). Abiotic stresses are a major hindrance to worldwide crop production, and are projected to affect roughly $20 \%$ of the total irrigated area worldwide, causing waste to $50 \%$ of the land by the mid-21st century (Mahajan and Tuteja, 2005). Of the total available cultivated area of 1.5 billion ha, $20 \%$ is irrigated, whereas $60 \%$ is rain-fed, contributing to 40 and $60 \%$, respectively, of total food production (Kosová et al., 2014). Wheat, an important crop worldwide, is severely affected by drought stress under both rain-fed and irrigated conditions. 
Climatic and various environmental constraints severely influence the production of wheat crop (Semenov et al., 2014). Limited water supply, thermal alterations and high salinity significantly impair the grain yields in wheat (Porter and Semenov, 2005). Potential yield losses associated with these stresses could be combated through the selection and adaptation of cultivars with improved genetic traits (Lobell and Gourdji, 2012; Reynolds et al., 2012). Nevertheless, abiotic stresses not only affect the yield, but also the quality of a crop product, i.e., nutritional value, aroma, color, flavor, and processing properties (Reynolds et al., 2012). Understanding the biochemical pathways, physiological impacts, and molecular mechanisms is highly important to combat these abiotic stresses through the genetic improvements in plants against stress tolerance, yield, and food quality (Hrmova and Lopato, 2014).

Stress biology is a multidisciplinary, integrated, and systematic study of biological systems that utilizes modern omics approaches to analyze genome, metabolome, transcriptome, and proteome under stress (Akpinar et al., 2015). The whole interactome for drought and salinity stress is obtained by the integration of data from relative gene expression, pools of metabolites, and the subsequent production of proteins under stress (Kosová et al., 2014; Kurtoglu et al., 2014). Plants have evolved intricate mechanisms by allowing optimal responses to enable adaptation or avoidance of the stress under such conditions (Hrmova and Lopato, 2014). These intricate mechanisms are usually regulated at the cellular level, such as changes in cell cycle regulation and cell division, membrane adjustments, cell wall modifications, synthesis of endogenic and low-molecular-weight molecules such as abscisic acid, ethylene, jasmonic acid, and salicylic acid (Hrmova and Lopato, 2014; Noctor et al., 2014). All elements that trigger specific mechanisms in response to abiotic stress signals are studied under the scope of stress systems biology (Table 1).

Over the course of time, systems biology has appeared as a promising field that integrates massive amounts of data from genome-wide technologies and involves the use of computational models to help understand the topology and dynamical function of the molecular systems that constitute and sustain an organism (Noctor et al., 2014; Pandey et al., 2017). A large number of collaborating networks of responses have been constructed for model plants under abiotic stresses. The main objective of this review is to elucidate the molecular dynamics of wheat under drought and salinity stress, as well as to develop comprehensive stress-signaling models that can integrate stress systems biology with omics. Various cellular processes and antioxidant mechanisms operate inside the cell system to counter the alterations induced in cellular homeostasis by drought and salinity (Pandey et al., 2017; Zang et al., 2017). Therefore, before discussing how various mechanisms act under such circumstances, we need to understand the basic dynamics of working systems to address the homeostatic alterations in wheat systems biology.

\section{ANTIOXIDANT SYSTEMS: DEFENSE, SIGNALING, AND STRESS REGULATION}

The production of intracellular ROS (reactive oxygen species) under optimal growth conditions are reactive chemical species. Under abiotic stress conditions, the $\mathrm{CO}_{2}$ uptake is limited, which causes stomatal closure and favors the photorespiratory production of superoxides, singlet oxygen, and $\mathrm{H}_{2} \mathrm{O}_{2}$ in the peroxisome due to over reduced photosynthetic electron transport chain (Noctor et al., 2014). Plasma membrane and the apoplast are the main sites for ROS generation in response to various exogenous environmental stimuli and endogenous signals. Hyper production of ROS under abiotic stresses cause extensive deregulation of cellular energetics and inhibition of physiological processes in plants, which further effects plant growth and yield. These overproduced ROS are highly reactive and toxic for the breakdown of proteins, lipids, and nucleic acids with a result in cell death and could also work as signals for the activation of stress response pathways (Gill and Tuteja, 2010; Baxter et al., 2014; You and Chan, 2015). To protect these cellular damages in plants against these overproduced ROS, an efficient enzymatic and non-enzymatic antioxidative system exists to modulate these ROS at low levels for signal transduction pathways. A dynamic equilibrium between ROS production and scavenging is usually disturbed when ROS production overwhelms the cellular scavenging capability (Pandey et al., 2017). This disequilibrium results in a sudden excess of ROS, commonly called oxidative stress (Zang et al., 2017). In these circumstances, antioxidative mechanism would be an instantaneous endogenic choice for the plants to counter ROS hyper production, under abiotic stresses which cause high ROS concentration and cellular damage inside the cell.

Plants possess antioxidant machinery for ROS scavenging and the protection of cells from oxidative damage. To sustain growth, production, metabolism, and development, as well as to overcome the potential damage by ROS to cellular parts, the balance between ROS generation and scavenging should be firmly regulated (Tang et al., 2014; Zang et al., 2017). This balance is maintained by both enzymatic and non-enzymatic antioxidants (Tang et al., 2014). Enzymatic antioxidants include glutathione reductase (GR), peroxidase (POX), glutathione peroxidase (GPX), ascorbate peroxidase (APX), catalase (CAT), superoxide dismutase (SOD), dehydroascorbate reductase (DHAR) and mono dehydroascorbate reductase (MDHAR) (Varga et al., 2012; Tang et al., 2014), whereas non-enzymatic antioxidants include phenolic compounds such as glutathione (GSH), carotenoids, tocopherol and ascorbate (Varga et al., 2012). Antioxidant enzymes work together to detoxify ROS and located at different sites within plant cells. Initially, the SOD antioxidant convert $\mathrm{O}_{2}$ into $\mathrm{H}_{2} \mathrm{O}_{2}$ and later on, CAT, APX, and GPX enzymes detoxify the $\mathrm{H}_{2} \mathrm{O}_{2}$ generated in the first step. Unlike CAT, APX needs non-enzymatic antioxidants such as GSH and ascorbic acid to reduce $\mathrm{H}_{2} \mathrm{O}_{2}$ with the help of MDHAR, DHAR, GR, GPX, and GST (Varga et al., 2012; Keunen et al., 2013). Conversely, PRX and organic hydroperoxides 
TABLE 1 | Specific dynamics of stress systems biology associated with abiotic stress signaling.

\begin{tabular}{|c|c|c|c|c|}
\hline $\begin{array}{l}\text { Molecular } \\
\text { processes }\end{array}$ & Sensing activities & $\begin{array}{l}\text { Signaling factors and } \\
\text { Receptors }\end{array}$ & Accessory proteins & Reference \\
\hline Signaling pathways & $\begin{array}{l}\text { Fluctuation in turgor of stomatal guard } \\
\text { cells as well as alteration in the levels of } \\
\text { cellular } \mathrm{K}^{+}, \mathrm{ABA} \text { and } \mathrm{pH}\end{array}$ & $\begin{array}{l}\text { PYLs, RCARs, PYR1 } \\
\text { (regulatory components } \\
\text { of ABA receptors) }\end{array}$ & MAPK, CIPK & $\begin{array}{l}\text { Pizzio et al., 2013; Kosová } \\
\text { et al., } 2014\end{array}$ \\
\hline $\begin{array}{l}\text { Genetic expression } \\
\text { and regulation }\end{array}$ & $\begin{array}{l}\text { Rise in the concentration of enzymes } \\
\text { responsible for JA biosynthesis } \\
\text { Enhanced production of salicylic acid }\end{array}$ & $\begin{array}{l}\text { ABF, AREB, NAC, CBF } \\
\text { CBF4, MYB, NAM, } \\
\text { MYC, DREB1, REB2 } \\
\text { (transcription factors) }\end{array}$ & $\begin{array}{l}\text { (ROS) scavenging enzymes, PR } \\
\text { proteins, 12-oxophytodienoate } \\
\text { reductase }\end{array}$ & $\begin{array}{l}\text { Alvarez et al., 2014; Kosová } \\
\text { et al., 2014, } 2015\end{array}$ \\
\hline Protein metabolism & $\begin{array}{l}\text { Alterations in complete translational } \\
\text { machinery along with protein } \\
\text { biosynthesis }\end{array}$ & $\begin{array}{l}\text { Elongation factor } \\
\text { eEF- } 1 \alpha\end{array}$ & $\begin{array}{l}\text { E1 to E3 components ubiquitin } \\
\text { ligase complex }\end{array}$ & $\begin{array}{l}\text { Ghabooli et al., 2013; } \\
\text { Kosová et al., } 2015\end{array}$ \\
\hline $\begin{array}{l}\text { Amino acid } \\
\text { metabolism }\end{array}$ & $\begin{array}{l}\text { Increased } S \text {-adenosylmethione, } \\
\text { Phenylalanine, } \gamma \text {-aminobutyric acid } \\
\text { (GABA), proline, tryptophan, tyrosine, } \\
\text { phenylalanine, leucine, isoleucine, and } \\
\text { valine }\end{array}$ & $\begin{array}{l}\text { Methylation of } \\
\text { monolignols }\end{array}$ & SAMS, PAL. & $\begin{array}{l}\text { Bowne et al., 2012; } \\
\text { Faghani et al., 2015; } \\
\text { Shankar et al., } 2016\end{array}$ \\
\hline $\begin{array}{l}\text { Hormone } \\
\text { metabolism }\end{array}$ & $\begin{array}{l}\text { Upregulation of } \\
\text { abiotic-stress-associated hormones } \\
\text { such as JA, ABA, and SA }\end{array}$ & $\begin{array}{l}\text { GA2OX1 (involved in } \\
\text { gibberellin signaling), } \\
\text { GID1L2 (gibberellin } \\
\text { receptor involved in } \\
\text { gibberellin signaling) }\end{array}$ & $\begin{array}{l}\text { DELLA proteins, 9-cis- } \\
\text { epoxycarotenoid-dioxygenase }\end{array}$ & $\begin{array}{l}\text { Krugman et al., 2011; } \\
\text { Kosová et al., 2015; } \\
\text { Shankar et al., } 2016\end{array}$ \\
\hline Energy metabolism & $\begin{array}{l}\text { Rise and fall in the levels of various } \\
\text { proteins related to respiration, } \\
\text { ATP-biosynthesis, and respiration }\end{array}$ & $\begin{array}{l}\text { RubisCO LSU, PSI } \\
\text { Fe-S, PSII LHC protein, } \\
\text { and SSU } \\
\text { (photosynthesis related } \\
\text { transcripts) }\end{array}$ & $\begin{array}{l}\text { PGK, PRK, RubisCO activase, } \\
\text { pyruvate kinase, alcohol } \\
\text { dehydrogenase, and } \\
\text { 2,3-bisphosphoglycerate- } \\
\text { independent phosphoglycerate } \\
\text { mutase. }\end{array}$ & $\begin{array}{l}\text { Kosová et al., 2015; } \\
\text { Vítámvás et al., } 2015\end{array}$ \\
\hline $\begin{array}{l}\text { Stress-responsive } \\
\text { proteins }\end{array}$ & $\begin{array}{l}\text { Increased deposition of hydrophilic } \\
\text { proteins and osmolytes with chaperone } \\
\text { functions }\end{array}$ & $\begin{array}{l}\text { GABA and polyamines, } \\
\text { dehydrin protein DHN5 }\end{array}$ & $\begin{array}{l}\text { HSP70, HSP90, HSP100, PDI, } \\
\text { P5CS }\end{array}$ & $\begin{array}{l}\text { Vítámvás et al., 2015; } \\
\text { Bevan et al., } 2017\end{array}$ \\
\hline Cellular transport & $\begin{array}{l}\text { Variation in protein ingredients } \\
\text { determining both membrane and } \\
\text { cytoplasmic transport }\end{array}$ & & Actin, Annexins & $\begin{array}{l}\text { Zhang et al., 2014; } \\
\text { Vítámvás et al., } 2015\end{array}$ \\
\hline $\begin{array}{l}\text { Metabolic activities } \\
\text { monitoring the cell } \\
\text { wall }\end{array}$ & $\begin{array}{l}\text { Disruption in the metabolism of lignin } \\
\text { and polyglucan, which is associated } \\
\text { with reduced cell wall extensibility }\end{array}$ & $\begin{array}{l}\text { Extensin, ABA, } \\
\text { glycine-rich protein, } \\
\text { and germin }\end{array}$ & XET, PAL, COMT, caffeoyl-CoA, & $\begin{array}{l}\text { Krugman et al., 2011; } \\
\text { Alvarez et al., 2014; } \\
\text { Shankar et al., } 2016\end{array}$ \\
\hline $\begin{array}{l}\text { Recovery after } \\
\text { stress }\end{array}$ & $\begin{array}{l}\text { Transcripts of many drought-associated } \\
\text { genes such as sugar transporters and } \\
\text { protein kinases show downregulation }\end{array}$ & $\begin{array}{l}\text { Cytochrome P450, } \\
\text { COR410 SDi-6, } \\
\text { HCF136, tubulin } \alpha-2 \text {, } \\
\text { and OEE2 }\end{array}$ & $\begin{array}{l}\text { Polyubiquitin, peroxidases, } \\
\text { P5CS, HSP60, and CCOMT }\end{array}$ & $\begin{array}{l}\text { Ford et al., 2011; Hao } \\
\text { et al., } 2015\end{array}$ \\
\hline $\begin{array}{l}\text { Mechanisms during } \\
\text { grain-filling phase }\end{array}$ & $\begin{array}{l}\text { Chlorophyll degradation in spike organs } \\
\text { indicates a reduced oxidative owing to } \\
\text { decreased rates of photosynthesis }\end{array}$ & & $\begin{array}{l}\text { Chlorophyllase, pheophorbide a } \\
\text { oxygenase }\end{array}$ & $\begin{array}{l}\text { Shankar et al., 2016; } \\
\text { Vu et al., } 2017\end{array}$ \\
\hline
\end{tabular}

use the GSH, thioredoxin (TRX), or glutaredoxin (GRX) as nucleophiles through ascorbate-independent thiol-mediated pathways (Keunen et al., 2013). Non-enzymatic antioxidants are also crucial for ROS homeostasis in plants and include carotenoids, flavonoids, GSH, AsA, and tocopherols (Tang et al., 2014). Besides traditional enzymatic and non-enzymatic antioxidants, soluble sugars, including raffinose, fructose, glucose including various disaccharides and oligosaccharides, also have a role with respect to ROS detoxification (Keunen et al., 2013). The production rates of ROS are directly linked with soluble sugars, which regulate mitochondrial respiration or photosynthesis metabolic pathways to detoxify ROS (Pandey et al., 2017). On the other hand, they also feed NADPH-producing metabolic pathways to contribute to antioxidative progressions (Kong et al., 2013; Caverzan et al., 2016).

Avoiding ROS production under abiotic stress conditions might also be more important to maintain ROS homeostasis than the antioxidative system (You and Chan, 2015). In the electron transport chains of mitochondria, the excess generation of ROS can be prevented by alternative oxidases (AOX) (Niu and Liao, 2016). AOX pathway can also decrease the electron leaking possibility to $\mathrm{O}_{2}$ to generate super-oxide by diverting the electrons flowing through electron-transport chains. Additional mechanisms, such as the rearrangement of the photosynthetic 
apparatus, leaf movement, and curling might also signify an effort to avoid the over-reduction of ROS by harmonizing the amount of energy absorbed by the plant as well as $\mathrm{CO}_{2}$ availability (Mittler, 2002). In wheat, alterations in the activity of antioxidant enzymes POX, SOD, CAT, APX, and GR (Caverzan et al., 2016), and in the level of ROS (Kong et al., 2013) during abiotic stress have been reported to counter oxidative stress (Talaat and Shawky, 2014). Correspondingly, these findings reveal activation of the ROS scavenging processes in wheat. The alteration in the antioxidant activity of these enzymes in wheat is a defense mechanism to avoid oxidative damage under abiotic stress (Xu et al., 2013). High concentrations of ROS are deleterious to the plant, and therefore, the activation of both enzymatic and nonenzymatic entities triggers redox homeostasis to eliminate toxic levels of ROS (Varga et al., 2012). However, studies have revealed that different genotypes of wheat show differential responses to the same stress condition. The higher antioxidant ability of tolerant genotypes is related to their genetic architecture and protects them from severe oxidative damage. Furthermore, the complexity of ROS production and scavenging mechanisms in wheat is determined by the length and intensity of stress, as well as the developmental stage and tissue type.

Similarly, the stress type, intensity, and duration also regulate the production of $\mathrm{H}_{2} \mathrm{O}_{2}$, and its concentration differs across various cellular compartments (Talaat and Shawky, 2014). In biological systems, $\mathrm{H}_{2} \mathrm{O}_{2}$ is one of the most abundant ROS; it causes high toxicity due to its high reactivity ( $\mathrm{Xu}$ et al., 2013). It is a signaling factor that triggers various responses in plant cells to counter abiotic stresses. Several factors such as production site, type of stress, and exposure time, as well as concentration, determine the biological effect of $\mathrm{H}_{2} \mathrm{O}_{2}$ (Petrov and Van Breusegem, 2012; Xu et al., 2013). At low concentrations, $\mathrm{H}_{2} \mathrm{O}_{2}$ serves as a signaling molecule, owing to its ability to diffuse across plasma membranes and its compartmentalization in cellular organelles, and thus elicits the stress response in crop plant (Petrov and Van Breusegem, 2012). Recent studies have revealed that, in wheat, early $\mathrm{H}_{2} \mathrm{O}_{2}$ treatment improves tolerance to abiotic stresses; however, these responses are not completely elucidated in adult plants at their final growth stages (Petrov and Van Breusegem, 2012; Talaat and Shawky, 2014). Studies conducted on the stress physiology of biological systems have demonstrated varying physiological responses at different developmental stages. Ge et al. (2013) have reported that $\mathrm{H}_{2} \mathrm{O}_{2}$ acts as both a signaling molecule and a deleterious agent in wheat seedlings under stress. Correspondingly, the concentration of $\mathrm{H}_{2} \mathrm{O}_{2}$ determines its beneficial or toxic role in plants. Following $\mathrm{H}_{2} \mathrm{O}_{2}$ signaling, various signaling entities such as miRNAs, transcription factors, and MAP-kinases participate in transduction networks (Petrov and Van Breusegem, 2012). Moreover, $\mathrm{H}_{2} \mathrm{O}_{2}$ production sites, concentrations, and crosstalk with other signaling pathways also play an important role in determining the subsequent response (Ge et al., 2013). Hence, the processes by which ROS scavenging counters different stresses need to be investigated further as several other biochemical, genetic, and molecular pathways could be involved in and contribute to this tolerance (You and Chan, 2015).

\section{SALINITY TOLERANCE: SIGNALING, GENE EXPRESSION, AND REGULATION PROTOTYPE}

Wheat plants utilizes phenotypic plasticity to mitigate the effects of salinity stress by upregulating of various stress responsive genes including ion transporters, transcriptional factors, signaling pathway modifiers, osmolytes production and antioxidative enzymes (Ge et al., 2013). Numerous pathway responses that altered due to the salinity mark the salt-responsive genes in tolerant plants which facilitate to understand the expression prototype of existing genes during the whole span of stress (Darko et al., 2017). Many genes are implicated in salinity tolerance; however, a comprehensive investigation is needed to resolve the complexity of the response to salinity stress at the genomic level (Abogadallah, 2010; Darko et al., 2017). Unification of systems biology and omics could specifically elucidate the genomic and metabolic responses of cells in a precise manner, providing better insights into various interconnecting signaling process that regulate cellular homeostatic machinery during stress.

High salinity level creates ionic imbalance and hypertonic effects, which inhibit crop yield at the molecular, biochemical, and physiological levels, either directly or indirectly (Abogadallah, 2010). Moreover, salinity stress is predicted to hamper photosynthesis, enhance photorespiration, deactivate enzymes, increase ROS damage, and ultimately lead to chloroplast damage. Hence, plants have developed various processes, including salt exclusion and compartmentalization (Zhang et al., 2016), to effect the successive biological and physiological changes that mitigate the harmful effects of salt stress (Darko et al., 2017). This phenotypic plasticity is governed by the upregulation and downregulation of different genes to decrease or protect from ROS damage, reformulate osmotic and ionic balance, and resume growth during high levels of salinity stress (Liu et al., 2014).

To elucidate the molecular dynamics of salt tolerance and increase the productivity of crops, substantial efforts has been made to develop genetic model systems. ROS scavenging is an efficient means mitigate oxidative damage and manipulate the expression of associated genes such as those encoding SOD, APX, and GRs, which provide salt tolerance (Abogadallah, 2010). Vacuolar compartmentalization maintains $\mathrm{Na}^{+} / \mathrm{K}^{+}$, and thereby also enhances salt tolerance.

Zhang et al. (2016) reported three pathways governing the salinity counter mechanisms in cotton. However, we proposed a salinity counter model for wheat that demonstrates how various genetic determinants are regulated via different pathways, ultimately leading to cellular homeostasis (Figure 1). The cell membrane is equipped with proteins serving as $\mathrm{Na}^{+}$receptors, which receive stress signals and elicit the production of signaling entities like $\mathrm{Ca}^{2+}$, ROS, and hormones (Liu et al., 2014). The elevated levels of these entities trigger three pathways that ultimately activate SOS1 to pump out $\mathrm{Na}^{+}$from the cytosol. All the genes determining these pathways are upregulated. However, in this salinity counter mechanism, the photosynthesis process is 


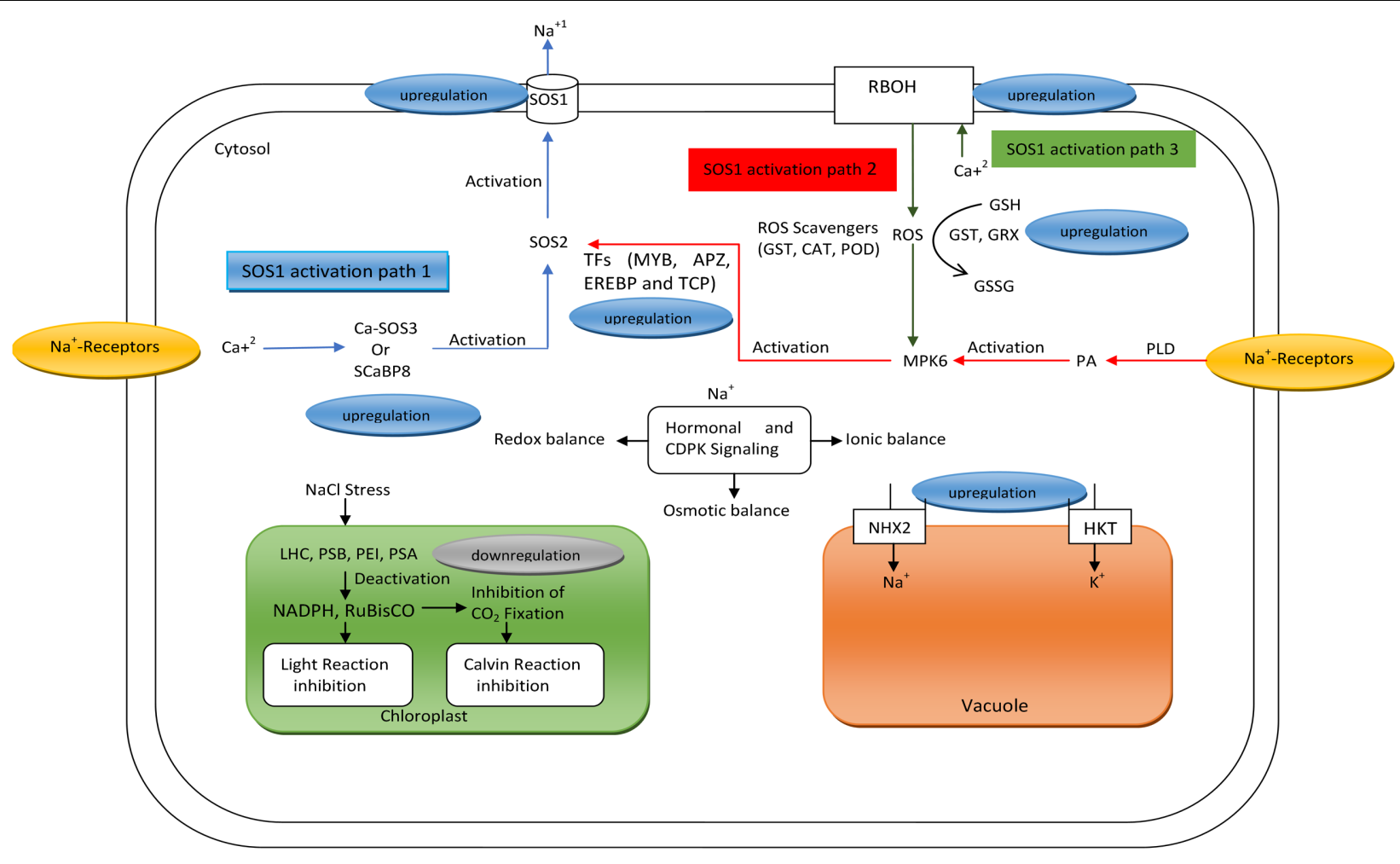

FIGURE 1 | Model depicting the regulation of genes during different pathways to counter the effects of salinity in wheat leaf cells. $(\rightarrow)$ Indicting first pathway involved in the activation of SOS1, $(\rightarrow)$ Indicating second pathway involved in the activation of SOS1, $(\rightarrow)$ indicating third pathway involved in the activation of SOS1, $(\rightarrow)$ Indicating the occurrence of systematic processes in cytosol, chloroplast and vacuole under salt stress. RBOH, respiratory burst oxidase homologs; SOS, salt overly sensitive; SCaBP8, SOS3-like calcium binding protein8; GST, glutathione S-transferase; CAT, Catalase; POD, peroxidase; GRX, glutaredoxins; CDPK,

calcium-dependent protein kinase; MPK6, mitogen-activated protein kinase6; PA, phosphatidic acid; PLD, Phospholipase D.

inhibited, as RuBisCO and NADPH are deactivated (Zhao et al., 2014) owing to the down regulation of genes like LHC, PSB, PEI, and PSA (Liu et al., 2014).

However, an excess of $\mathrm{Na}^{+}$hinders the uptake of $\mathrm{K}^{+}$and cytosolic enzymes (Chao et al., 2013). The activity of $\mathrm{Na}^{+}$and $\mathrm{K}^{+}$ transporters and $\mathrm{H}^{+}$pumps and SOS2 and SOS3 protein kinase pathways coordinates with SOS1 to trigger the sequestration and secretion of toxic $\mathrm{Na}^{+}$in the cell (Figure 1). Therefore, salttolerant genotypes resume growth at a slow rate when subjected to salt stress, owing to regulation by hormones and cell-division related genes. Increased deposition of $\mathrm{ABA}$ in response to salt stress is thought to upregulate cyclin-dependent protein kinase inhibitor (ICK1), which inhibits cell division (Wilkinson and Davies, 2010; Lee and Luan, 2012; Liu et al., 2015). Hence, these interconnected features constitute a breeding target for breeders to improve the potential range of adaptability of their germplasm to salt stress. The salinity tolerance of crop plants such as wheat is a multigenic trait, which is more complicated than in the model plant Arabidopsis, in addition to a high sensitivity to salinity (Shankar et al., 2016). Therefore, it is logical to conclude that wheat employs a more complicated system in response to salinity than Arabidopsis (Table 1).

Various genes have been reported to play a significant role in response to salt stress in wheat. For example, SRO (Similar to Rcd-One) mediates ROS deposition and scavenging by regulating the expression prototype of NADPH dehydrogenase and NADPH oxidase, together with GSH-peroxidase and ascorbate-GSH. Dynamic expression of these genes authenticates their inevitability and sufficiency in enhancing salt tolerance (Liu et al., 2014; Zhao et al., 2014). Nevertheless, the processes mediating the genome-wide gene expression in wheat to control the deleterious effects imposed by salinity are still not completely understood. Moreover, it has been reported, using a microarray approach, that out of 32,000 detected ESTs in wheat, 19\% were either up- or down-regulated (Kawaura et al., 2006, 2008).

The adaptability of plants to unfavorable environments has been also explained through polyploidization (Dubcovsky and Dvorak, 2007). For instance, tetraploid Arabidopsis has a greater tolerance to salt stress, via the homeostasis of $\mathrm{K}^{+}$and $\mathrm{Na}^{+}$, than diploid Arabidopsis (Chao et al., 2013). However, the molecular mechanisms determining adaptability to environmental stresses via this route are still poorly understood. It has recently been hypothesized that the expression of homologous genes is responsible for increased tolerance to salt stresses in polyploid plants. For example, in allopolyploid cotton (Gossypium hirsutum), one copy of the alcohol dehydrogenase A gene (AdhA) is upregulated under cold conditions, while the other responds to water stress (Liu and Adams, 2007). Moreover, 


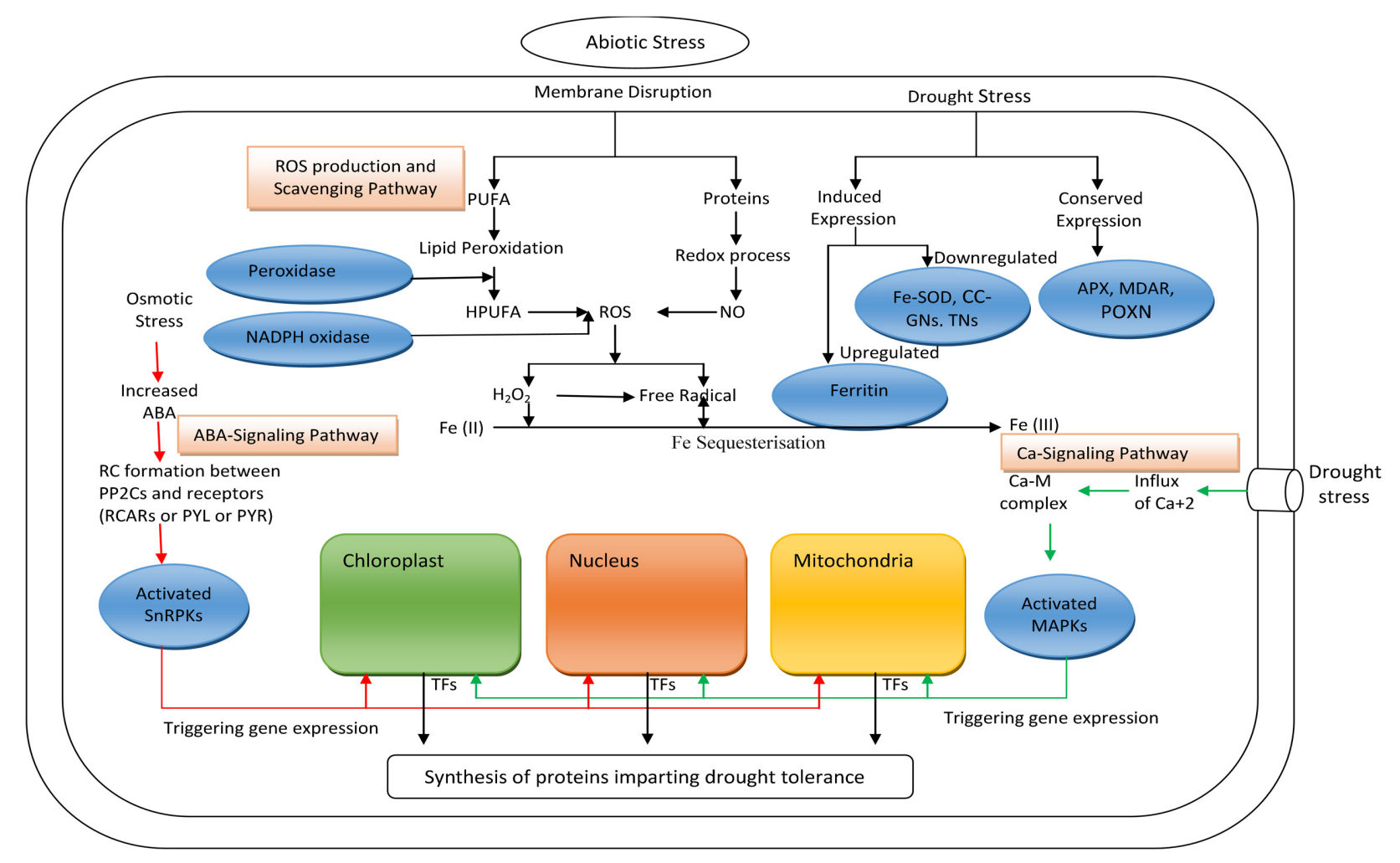

FIGURE 2 | Systematic model showing the operational hierarchy of signaling pathways in wheat leaf cells that counter the effects of drought stress. ( $\rightarrow$ ) Indicating ABA mediated signaling pathway for protein synthesis, $(\rightarrow)$ Indicating $\mathrm{Ca}^{2+}$ mediated signaling pathway for protein synthesis, $(\rightarrow)$ Indicating systematic changes involved in ROS production and scavenging pathway. PUFA, polyunsaturated fatty acids; HPUFA, hydroxy polyunsaturated fatty acids; ROS, reactive oxygen species; Fe-SOD, Fe-superoxide dismutase; CC-GNs, CC type glutaredoxins; TNs, thioredoxins; APX, ascorbate peroxidase; MDAR, monodehydroascorbate reductase; POXN, peroxiredoxin; SnRPKs, SNF1-related protein kinases; MAPK, mitogen-activated protein kinase; RC, regulatory component; PP2Os,

Phosphatases type-2C; TFs, transcription factors.

transcriptomic studies have reported that allohexaploid wheat manifests intensive partitioned expression of homeologs in response to drought and heat stress (Liu et al., 2015).

\section{DROUGHT TOLERANCE: SIGNALING, GENE EXPRESSION, AND REGULATION PROTOTYPE}

Wheat, with its large genome, is a genetically complex entity, and is hypothesized as an ideal system to investigate the signaling processes involved in mediating stress response (Kang and Udvardi, 2012). Successful chromosome-based draft sequencing in hexaploid wheat has facilitated the mining of genes that regulate these complex processes during drought signaling, further accelerating the breeding programs. Current developments in omics and systems biology would further help researchers to better understand the mechanisms that operate at a cellular level to mitigate drought stress (Wang et al., 2014). To date, many researchers have comprehensively described some of the molecular and physiological phenomena that help to mitigate drought stress in plants (Table 1). However, in wheat, the activation of various regulatory mechanisms, owing to different mediatory agents, leads toward the homeostasis of plant cell system.

Abscisic acid (ABA)-mediated signaling during drought stress leads to rapid stomatal closure that inhibits the loss of water from leaves (Wilkinson and Davies, 2010; Lee and Luan, 2012). Moreover, under drought conditions, reduced water potential leads to increased accumulation of $\mathrm{ABA}$, which regulates stress-related downstream responses (Aprile et al., 2013). Two major responses, osmotic adaptation and an increase in the concentration of osmolytes such as glycine betaine, glutamate, proline, and sugars (trehalose, sorbitol, and mannitol), appear at the cellular and molecular level to nullify drought effects by preventing membrane deterioration and enzyme inactivation (Slama et al., 2015). Furthermore, many drought-responsive genes and specific protective proteins are regulated for drought resistance (Ford et al., 2011). Signal transduction pathways regulate drought-stress-associated transcripts, proteins, reactive oxygen species (ROS) scavengers, and antioxidants (Faghani et al., 2015). ROS scavenging pathways protect the cell from oxidative damage under drought stress. Antioxidant enzymes, such as glutathione $S$-transferase (GST), APX, SOD, GR, GPX, and CAT, participate in ROS scavenging (Ford et al., 2011; Faghani et al., 2015). THz upregulation of these enzymes under 
drought stress indicates the presence of a potential system in plant cells to cope with drought stress.

In wheat, drought stress activates ROS generation and scavenging pathways and the $\mathrm{Ca}^{2+}$ and ABA signaling pathways, as depicted in (Figure 2). Under stress, genes manifest both induced and conserved expression. However, upregulation of ferritin plays an important role in ROS scavenging (Pizzio et al., 2013; Alvarez et al., 2014), as oxidation of Fe (II) to Fe (III) consumes $\mathrm{H}_{2} \mathrm{O}_{2}$ and oxygen $\left(\mathrm{O}_{2}\right)$ (Kosová et al., 2015) during Fe sequestration.

Although, extensive research has been conducted on plants to better understand the induction of drought responsive mechanisms (Kosová et al., 2015), the process is still poorly understood, owing to the complicated nature of this quantitative trait (Ashoub et al., 2013). Until now, limited knowledge is available on the molecular mechanisms of drought tolerance in wheat genotypes. Drought-inducible proteins isolated from different wheat organs, such as roots, seedling, leaves, stem, and grains, have been revealed to be differentially expressed, and this differential expression is responsible for the drought resistance of tolerant genotypes (Vítámvás et al., 2015). Proteome regulation in wheat takes place in three phases (Kosová et al., 2014) that are indicated in along with their categories, potential consequences, and signaling proteins (Table 2).

Pioneering transcriptome studies have documented that the drought-sensitive and tolerant genotypes of wheat are equipped with different molecular mechanisms to mitigate drought stress (Mohammadi et al., 2007; Aprile et al., 2013). A number of drought-related genes showing constitutive expression in tolerant wheat genotypes are also known to be triggered in drought-sensitive genotypes, and such expression is a limiting attribute in the understanding of response mechanisms induced by drought (Aprile et al., 2013). Moreover, hormonal and enzyme-based regulation pathways show variations in different wheat genotypes (Ergen and Budak, 2009). When tolerant genotypes are affected by drought stress, prompt activation of signal transduction pathways triggers downstream elements. Differential response of specific transcription factors in different wheat genotypes indicates the presence of different signaling pathways mediated by hormones. The induction of transcription factors that bind to ethylene-responsive elements has been reported in a sensitive wheat genotype, whereas the induction of bZIP and HDZIP genes transcription factors related to $\mathrm{ABA}$ regulation has also been reported in tolerant wheat genotypes under drought stress (Ergen and Budak, 2009). To date, these studies have provided a significant evidences about signaling dynamics in response to drought stress; however, the transcriptional responses are not sufficient to estimate posttranscriptional and post-translational modifications (PradetBalade et al., 2001). Moreover, little is known about the functional outputs of these detected genes, and hence, it is difficult to establish the relationship between transcriptome and proteome in drought-sensitive and tolerant wheat genotypes under stress.

Currently proteomics is becoming the most dynamic and direct accessory to unravel the function of expressed proteins under drought stress (Ford et al., 2011; Ghabooli et al., 2013). It can be complemented by transcriptome studies to generate a global expression profile of proteins encoded by the genome (Bowne et al., 2012; Vu et al., 2017). Comparative proteome profiling of tolerant and sensitive genotypes could also help to

TABLE 2 | Phases of proteome regulations in wheat under drought stress with their categories, potential consequences, and signaling.

\begin{tabular}{|c|c|c|c|c|}
\hline Proteome phase & Categories & Consequences & Signaling proteins & Reference \\
\hline Alarm phase & $\begin{array}{l}\text { Stress signaling and } \\
\text { gene Expression }\end{array}$ & $\begin{array}{l}\text { Alterations in physiochemical characteristics of } \\
\text { plasma membrane. Phytohormones like ABA, } \\
\text { JA, SA, and others show upregulation }\end{array}$ & $\begin{array}{l}\text { G-proteins, PLC, PLD, } \\
\text { MAPK, CDPK, PP2C, } \\
\text { Aquaporins }\end{array}$ & $\begin{array}{l}\text { Alvarez et al., 2014; Kosová } \\
\text { et al., 2015; Montenegro } \\
\text { et al., } 2017\end{array}$ \\
\hline \multirow[t]{2}{*}{ Acclimation phase } & Protein metabolism & $\begin{array}{l}\text { Regulatory changes in cell cycle and } \\
\text { programmed cell death (PCD). Metabolic } \\
\text { activities associated with protein degradation } \\
\text { and biosynthesis show continuous alterations }\end{array}$ & $\begin{array}{l}\text { elF5A, TCTP, SAM, IDI2, } \\
\text { IDS2, IDS3 }\end{array}$ & Kosová et al., 2014, 2015 \\
\hline & Energy metabolism & $\begin{array}{l}\text { Changes in various protein metabolisms have } \\
\text { direct impacts on energy metabolism. A fall in } \\
\text { the levels RuBisCO as well as Calvin cycle } \\
\text { enzymes PRK, PGK, and transketolase. }\end{array}$ & $\begin{array}{l}\text { OEE1, OEE2, CPN60- } \alpha \text {, } \\
\text { CPN60- } \beta \text {, TPI, 20-kDa, } \\
\text { GAPDH, Enolase, } \\
\beta \text {-conglycinin }\end{array}$ & $\begin{array}{l}\text { Kosová et al., 2015; } \\
\text { Mostek et al., 2015; Cheng } \\
\text { et al., } 2016\end{array}$ \\
\hline \multirow[t]{2}{*}{ Resistance phase } & $\begin{array}{l}\text { Stress-protective } \\
\text { proteins }\end{array}$ & $\begin{array}{l}\text { Improper protein folding of HSPs due to the } \\
\text { absence of hydration envelopes. Upregulation } \\
\text { of Protein disulfide isomerase. Rise in } \\
\text { ROS-scavenging enzymes increases the risks } \\
\text { of protein damage }\end{array}$ & $\begin{array}{l}\text { HSP110, HSP90, HSP70, } \\
\text { HSP60, GDC, NADP- } \\
\text { ME3,NADP-ME4,TSI-1 } \\
\text { protein }\end{array}$ & $\begin{array}{l}\text { Fercha et al., 2014; Kosová } \\
\text { et al., 2015; Mostek et al., } \\
2015\end{array}$ \\
\hline & Structural proteins & $\begin{array}{l}\text { Cellular transport and cytoskeleton get impaired } \\
\text { profoundly. An increase in aquaporin proteins } \\
\text { and its differential phosphorylation. Rate of cell } \\
\text { division and plant growth decrease significantly. } \\
\text { Increased cell wall lignification }\end{array}$ & $\begin{array}{l}\text { VDAC, SAM, CCOMT, } \\
\text { COMT. }\end{array}$ & $\begin{array}{l}\text { Witzel et al., 2014; Kosová } \\
\text { et al., 2015; Cheng et al., } \\
2016\end{array}$ \\
\hline
\end{tabular}

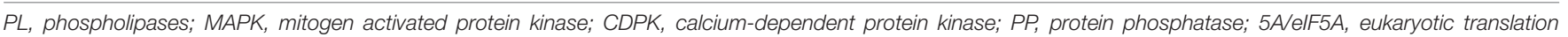

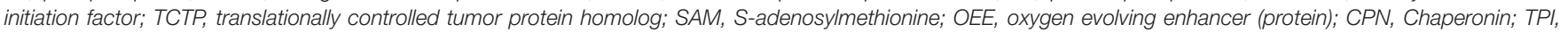

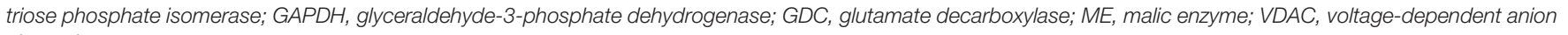
channel. 
explain the complexity of induced molecular processes in wheat during drought stress (Krugman et al., 2011). To date, only a few studies have been conducted to examine the proteomic alterations under stress in wheat genotypes (Bevan et al., 2017; Vu et al., 2017).

\section{CONCLUSION}

Exploitation of the mysterious genomic attributes that impart tolerance to abiotic stresses in wheat is a potential challenge for scientists. Although substantial efforts have been made in this direction, several research gaps need to be fulfilled. Therefore, integration of stress systems biology with recent omics approaches would be helpful in unraveling the potential mechanisms involved in countering abiotic stresses. This would

\section{REFERENCES}

Abogadallah, G. M. (2010). Insights into the significance of antioxidative defense under salt stress. Plant Signal. Behav. 5, 369-374. doi: 10.4161/psb.5.4. 10873

Akpinar, B. A., Kantar, M., and Budak, H. (2015). Root precursors of microRNAs in wild emmer and modern wheats show major differences in response to drought stress. Funct. Integr. Genomics 15, 587-598. doi: 10.1007/s10142-0150453-0

Alvarez, S., Roy Choudhury, S., and Pandey, S. (2014). Comparative quantitative proteomics analysis of the $\mathrm{ABA}$ response of roots of drought-sensitive and drought-tolerant wheat varieties identifies proteomic signatures of drought adaptability. J. Proteome Res. 13, 1688-1701. doi: 10.1021/pr40 $1165 \mathrm{~b}$

Aprile, A., Havlickova, L., Panna, R., Marè, C., Borrelli, G. M., Marone, D., et al. (2013). Different stress responsive strategies to drought and heat in two durum wheat cultivars with contrasting water use efficiency. BMC Genomics 14:821. doi: 10.1186/1471-2164-14-821

Ashoub, A., Beckhaus, T., Berberich, T., Karas, M., and Brüggemann, W. (2013). Comparative analysis of barley leaf proteome as affected by drought stress. Planta 237, 771-781. doi: 10.1007/s00425-012-1798-4

Baxter, A., Mittler, R., and Suzuki, N. (2014). ROS as key players in plant stress signalling. J. Exp. Bot. 65, 1229-1240. doi: 10.1093/jxb/ ert375

Bevan, M. W., Uauy, C., Wulff, B. B. H., Zhou, J., Krasileva, K., and Clark, M. D. (2017). Genomic innovation for crop improvement. Nature 543, 346-354. doi: 10.1101/gr.213405.116

Bowne, J. B., Erwin, T. A., Juttner, J., Schnurbusch, T., Langridge, P., Bacic, A., et al. (2012). Drought responses of leaf tissues from wheat cultivars of differing drought tolerance at the metabolite level. Mol. Plant 5, 418-429. doi: 10.1093/ $\mathrm{mp} / \mathrm{ssr} 114$

Caverzan, A., Casassola, A., and Brammer, S. P. (2016). Antioxidant responses of wheat plants under stress. Genet. Mol. Biol. 39, 1-6. doi: 10.1590/1678-4685GMB-2015-0109

Chao, D. Y., Dilkes, B., Luo, H., Douglas, A., Yakubova, E., Lahner, B., et al. (2013). Polyploids exhibit higher potassium uptake and salinity tolerance in Arabidopsis. Science 341, 658-659. doi: 10.1126/science. 1240561

Cheng, L., Wang, Y., He, Q., Li, H., Zhang, X., and Zhang, F. (2016). Comparative proteomics illustrates the complexity of drought resistance mechanisms in two wheat (Triticum aestivum L.) cultivars under dehydration and rehydration. BMC Plant Biol. 16:188. doi: 10.1186/s12870-016-0871-8

Darko, E., Gierczik, K., Hudák, O., Forgó, P., Pál, M., Türkösi, E., et al. (2017). Differing metabolic responses to salt stress in wheat-barley addition lines containing different 7H chromosomal fragments. PLOS ONE 12:e0174170. doi: 10.1371 /journal.pone. 0174170 provide a robust and focused dimension to crop improvement programs.

\section{AUTHOR CONTRIBUTIONS}

ZS, HR, MN, MA and TA came with idea and wrote the manuscript. ID, RA, and IR are reviewed and SY and GC critically analyzed the manuscript.

\section{FUNDING}

This work was funded by the Deanship of Scientific Research, King Abdulaziz University Jeddah. The authors acknowledge with thanks DSR technical and financial support.

Dubcovsky, J., and Dvorak, J. (2007). Genome plasticity a key factor in the success of polyploid wheat under domestication. Science 316, 1862-1866. doi: 10.1126/ science.1143986

Ergen, N. Z., and Budak, H. (2009). Sequencing over 13000 expressed sequence tags from six subtractive cDNA libraries of wild and modern wheats following slow drought stress. Plant Cell Environ. 32, 220-236. doi: 10.1111/j.1365-3040. 2008.01915.x

Faghani, E., Gharechahi, J., Komatsu, S., and Mirzaei, M. (2015). Comparative physiology and proteomic analysis of two wheat genotypes contrasting in drought tolerance. J. Proteomics 114, 1-15. doi: 10.1016/j.jprot.2014. 10.018

Fercha, A., Capriotti, A. L., Caruso, G., Cavaliere, C., Samperi, R., Stampachiacchiere, S., et al. (2014). Comparative analysis of metabolic proteome variation in ascorbate-primed and unprimed wheat seeds during germination under salt stress. J. Proteomics 108, 238-257. doi: 10.1016/j.jprot.2014.04.040

Ford, K. L., Cassin, A., and Bacic, A. (2011). Quantitative proteomic analysis of wheat cultivars with differing drought stress tolerance. Front. Plant Sci. 2:44. doi: 10.3389/fpls.2011.00044

Ge, P., Hao, P., Cao, M., Guo, G., Lv, D., Subburaj, S., et al. (2013). iTRAQbased quantitative proteomic analysis reveals new metabolic pathways of wheat seedling growth under hydrogen peroxide stress. Proteomics 13, 3046-3058. doi: 10.1002/pmic.201300042

Ghabooli, M., Khatabi, B., Ahmadi, F. S., Sepehri, M., Mirzaei, M., Amirkhani, A., et al. (2013). Proteomics study reveals the molecular mechanisms underlying water stress tolerance induced by Piriformospora indica in barley. J. Proteomics 94, 289-301. doi: 10.1016/j.jprot.2013.09.017

Gill, S. S., and Tuteja, N. (2010). Reactive oxygen species and antioxidant machinery in abiotic stress tolerance in crop plants. Plant Physiol. Biochem. 48, 909-930. doi: 10.1016/j.plaphy.2010.08.016

Hao, P., Zhu, J., Gu, A., Lv, D., Ge, P., Chen, G., et al. (2015). An integrative proteome analysis of different seedling organs in tolerant and sensitive wheat cultivars under drought stress and recovery. Proteomics 15, 1544-1563. doi: 10.1002/pmic.201400179

Hrmova, M., and Lopato, S. (2014). "Enhancing abiotic stress tolerance in plants by modulating properties of stress responsive transcription factors," in Genomics of Plant Genetic Resources, eds R. Tuberosa, A. Graner, and E. Frison (Dordrecht: Springer), 291-316. doi: 10.1007/978-94-007-7575-6_12

Kang, Y., and Udvardi, M. (2012). Global regulation of reactive oxygen species scavenging genes in alfalfa root and shoot under gradual drought stress and recovery. Plant Signal. Behav. 7, 539-543. doi: 10.4161/psb. 19780

Kawaura, K., Mochida, K., and Yamazaki, Y. (2006). Transcriptome analysis of salinity stress responses in common wheat using a $22 \mathrm{k}$ oligo-DNA microarray. Funct. Integr. Genomics 6, 132-142. doi: 10.1007/s10142-0050010-3 
Kawaura, K., Mochida, L., and Ogihara, Y. (2008). Genome-wide analysis for identification of salt-responsive genes in common wheat. Funct. Integr. Genomics 8, 277-286. doi: 10.1007/s10142-008-0076-9

Keunen, E., Peshev, D., Vangronsveld, J., Van Den Ende, W., and Cuypers, A. (2013). Plant sugars are crucial players in the oxidative challenge during abiotic stress: extending the traditional concept. Plant Cell Environ. 36, 1242-1255. doi: $10.1111 /$ pce. 12061

Kong, L., Wang, F., Si, J., Feng, B., Zhang, B., Li, S., et al. (2013). Increasing in ROS levels and callose deposition in peduncle vascular bundles of wheat (Triticum aestivum L.) grown under nitrogen deficiency. J. Plant Interact. 8, 109-116. doi: 10.1080/17429145.2012.712723

Kosová, K., Vítámvás, P., and Prášil, I. T. (2014). Proteomics of stress responses in wheat and barley-search for potential protein markers of stress tolerance. Front. Plant Sci. 5:711. doi: 10.3389/fpls.2014.00711

Kosová, K., Vítámvás, P., Urban, M. O., Klíma, M., Roy, A., and Prášil, T. A. (2015). Biological networks underlying abiotic stress tolerance in temperate crops-a proteomic perspective. Int. J. Mol. Sci. 16, 20913-20942. doi: 10.3390/ ijms160920913

Krugman, T., Peleg, Z., Quansah, L., Chagué, V., Korol, A. B., Nevo, E., et al. (2011). Alteration in expression of hormone-related genes in wild emmer wheat roots associated with drought adaptation mechanisms. Funct. Integr. Genomics 11, 565-583. doi: 10.1007/s10142-011-0231-6

Kurtoglu, K. Y., Kantar, M., and Budak, H. (2014). New wheat microRNA using whole-genome sequence. Funct. Integr. Genomics 14, 363-379. doi: 10.1007/ s10142-013-0357-9

Lee, S. C., and Luan, S. (2012). ABA signal transduction at the crossroad of biotic and abiotic stress responses. Plant Cell Environ. 35, 53-60. doi: 10.1111/j.13653040.2011.02426.x

Liu, S., Liu, S., Wang, M., Wei, T., Meng, C., Wang, M., et al. (2014). A wheat SIMILAR TO RCD-ONE gene enhances seedling growth and abiotic stress resistance by modulating redox homeostasis and maintaining genomic integrity. Plant Cell 26, 164-180. doi: 10.1105/tpc.113.118687

Liu, W., Xu, L., Wang, Y., Shen, H., Zhu, X., Zhang, K., et al. (2015). Transcriptome-wide analysis of chromium-stress responsive microRNAs to explore miRNA-mediated regulatory networks in radish (Raphanus sativus L.). Sci. Rep. 5:14024. doi: 10.1038/srep14024

Liu, Z., and Adams, K. L. (2007). Expression partitioning between genes duplicated by polyploidy under abiotic stress and during organ development. Curr. Biol. 17, 1669-1674. doi: 10.1016/j.cub.2007.08.030

Lobell, D. B., and Gourdji, S. M. (2012). The influence of climate change on global crop productivity. Plant Physiol. 160, 1686-1697. doi: 10.1104/pp.112. 208298

Mahajan, S., and Tuteja, N. (2005). Cold, salinity and drought stresses: an overview. Arch. Biochem. Biophys. 444, 139-158. doi: 10.1016/j.abb.2005.10.018

Mittler, R. (2002). Oxidative stress, antioxidants and stress tolerance. Trends Plant Sci. 7, 405-410. doi: 10.1016/S1360-1385(02)02312-9

Mochida, K., and Shinozaki, K. (2013). Unlocking Triticeae genomics to sustainably feed the future. Plant Cell Physiol. 54, 1931-1950. doi: 10.1093/pcp/ pct163

Mohammadi, M., Kav, N. N., and Deyholos, M. K. (2007). Transcriptional profiling of hexaploid wheat (Triticum aestivum L.) roots identifies novel, dehydrationresponsive genes. Plant Cell Environ. 30, 630-645. doi: 10.1111/j.1365-3040. 2007.01645.x

Montenegro, J. D., Golicz, A. A., Bayer, P. E., Hurgobin, B., Lee, H., Chan, C. K. K., et al. (2017). The pangenome of hexaploid bread wheat. Plant J. 90, 1007-1013. doi: $10.1111 /$ tpj.13515

Mostek, A., Börner, A., Badowiec, A., and Weidner, S. (2015). Alterations in root proteome of salt-sensitive and tolerant barley lines under salt stress conditions. J. Plant Physiol. 174, 166-176. doi: 10.1016/j.jplph.2014.08.020

Niu, L., and Liao, W. (2016). Hydrogen peroxide signaling in plant development and abiotic responses: crosstalk with nitric oxide and calcium. Front. Plant Sci. 7:230. doi: 10.3389/fpls.2016.00230

Noctor, G., Mhamdi, A., and Foyer, C. H. (2014). The roles of reactive oxygen metabolism in drought: not so cut and dried. Plant Physiol. 164, 1636-1648. doi: $10.1104 /$ pp.113.233478

Pandey, S., Fartyal, D., Agarwal, A., Shukla, T., James, D., Kaul, T., et al. (2017). Abiotic stress tolerance in plants: myriad roles of ascorbate peroxidase. Front. Plant Sci. 8:581. doi: 10.3389/fpls.2017.00581
Petrov, V. D., and Van Breusegem, F. (2012). Hydrogen peroxide-a central hub for information flow in plant cells. AoB Plants 2012, pls014. doi: 10.1093/aobpla/ pls014

Pizzio, G. A., Rodriguez, L., Antoni, R., Gonzalez-Guzman, M., Yunta, C., Merilo, E., et al. (2013). The PYL4 A194T mutant uncovers a key role of PYR1LIKE4/PROTEIN PHOSPHATASE 2CA interaction for abscisic acid signaling and plant drought resistance. Plant Physiol. 163, 441-455. doi: 10.1104/pp.113. 224162

Porter, J. R., and Semenov, M. A. (2005). Crop responses to climatic variation. Philos. Trans. R. Soc. Lond. B Biol. Sci. 360, 2021-2035. doi: 10.1098/rstb2005. 1752

Pradet-Balade, B., Boulmé, F., Beug, H., Müllner, E. W., and Garcia-Sanz, J. A. (2001). Translation control: bridging the gap between genomics and proteomics? Trends Biochem. Sci. 26, 225-229.

Reynolds, M., Foulkes, J., Furbank, R., Griffiths, S., King, J., Murchie, E., et al. (2012). Achieving yield gains in wheat. Plant Cell Environ. 35, 1799-1823. doi: 10.1111/j.1365-3040.2012.02588.x

Semenov, M. A., Stratonovitch, P., Alghabari, F., and Gooding, M. J. (2014). Adapting wheat in Europe for climate change. J. Cereal Sci. 59, 245-256. doi: 10.1016/j.jcs.2014.01.006

Shankar, R., Bhattacharjee, A., and Jain, M. (2016). Transcriptome analysis in different rice cultivars provides novel insights into desiccation and salinity stress responses. Sci. Rep. 6:23719. doi: 10.1038/srep23719

Slama, I., Abdelly, C., Bouchereau, A., Flowers, T., and Savouré, A. (2015). Diversity, distribution and roles of osmoprotective compounds accumulated in halophytes under abiotic stress. Ann. Bot. 115, 433-447. doi: 10.1093/aob/ mcu239

Talaat, N. B., and Shawky, B. T. (2014). Modulation of the ROS-scavenging system in salt-stressed wheat plants inoculated with arbuscular mycorrhizal fungi. J. Plant Nutr. Soil Sci. 177, 199-207. doi: 10.1002/jpln.201200618

Tang, W., He, Y., Tu, L., Wang, M., Li, Y., Ruan, Y. L., et al. (2014). Downregulating annexin gene GhAnn2 inhibits cotton fiber elongation and decreases $\mathrm{Ca}^{2+}$ influx at the cell apex. Plant Mol. Biol. 85, 613-625. doi: 10.1007/s11103014-0208-7

Varga, B., Janda, T., László, E., and Veisz, O. (2012). Influence of abiotic stresses on the antioxidant enzyme activity of cereals. Acta Physiol. Plant. 34, 849-858. doi: 10.1007/s11738-011-0882-x

Vítámvás, P., Urban, M. O., Škodáèek, Z., Kosová, K., Pitelková, I., Vítámvás, J., et al. (2015). Quantitative analysis of proteome extracted from barley crowns grown under different drought conditions. Front. Plant Sci. 6:479. doi: 10.3389/ fpls.2015.00479

Vu, L. D., Verstraeten, I., Stes, E., Van Bel, M., Coppens, F., Gevaert, K., et al. (2017). Proteome profiling of wheat shoots from different cultivars. Front. Plant Sci. 8:332. doi: $10.3389 /$ fpls.2017.00332

Wang, J., Ding, B., Guo, Y., Li, M., Chen, S., Huang, G., et al. (2014). Overexpression of a wheat phospholipase $\mathrm{D}$ gene, $\mathrm{TaPLD} \alpha$, enhances tolerance to drought and osmotic stress in Arabidopsis thaliana. Planta 240, 103-115. doi: 10.1007/s00425-014-2066-6

Wang, W., Vinocur, B., and Altman, A. (2003). Plant responses to drought, salinity and extreme temperatures: towards genetic engineering for stress tolerance. Planta 218, 1-14. doi: 10.12691/wjar-4-1-1

Wilkinson, S., and Davies, W. J. (2010). Drought, ozone, ABA and ethylene: new insights from cell to plant to community. Plant Cell Environ. 33, 510-525. doi: 10.1111/j.1365-3040.2009.02052.x

Witzel, K., Matros, A., Strickert, M., Kaspar, S., Peukert, M., Mühling, K. H., et al. (2014). Salinity stress in roots of contrasting barley genotypes reveals time-distinct and genotype-specific patterns for defined proteins. Mol. Plant 7, 336-355. doi: 10.1093/mp/sst063

Xu, C., Liu, Z., Zhang, L., Zhao, C., Yuan, S., and Zhang, F. (2013). Organization of actin cytoskeleton during meiosis I in a wheat thermo-sensitive genic male sterile line. Protoplasma 250, 415-422. doi: 10.1007/s00709-0120386-6

You, J., and Chan, Z. (2015). ROS regulation during abiotic stress responses in crop plants. Front. Plant Sci. 6:1092. doi: 10.3389/fpls.2015.01092

Zang, X., Geng, X., Wang, F., Liu, Z., Zhang, L., Zhao, Y., et al. (2017). Overexpression of wheat ferritin gene TaFER-5B enhances tolerance to heat stress and other abiotic stresses associated with the ROS scavenging. BMC Plant Biol. 17:14. doi: 10.6084/m9.figshare.c.3666352 
Zhang, F., Zhu, G., Du, L., Shang, X., Cheng, C., Yang, B., et al. (2016). Genetic regulation of salt stress tolerance revealed by RNA-Seq in cotton diploid wild species, Gossypium davidsonii. Sci. Rep. 6:20582. doi: 10.1038/srep 20582

Zhang, M., Lv, D., Ge, P., Bian, Y., Chen, G., Zhu, G., et al. (2014). Phosphoproteome analysis reveals new drought response and defense mechanisms of seedling leaves in bread wheat (Triticum aestivum L.). J. Proteomics 109, 290-308. doi: 10.1016/j.jprot.2014.07.010

Zhao, Y., Dong, W., Zhang, N., Ai, X., Wang, M., Huang, Z., et al. (2014). A wheat allene oxide cyclase gene enhances salinity tolerance via jasmonate signaling. Plant Physiol. 164, 1068-1076. doi: 10.1104/pp.113.227595
Conflict of Interest Statement: The authors declare that the research was conducted in the absence of any commercial or financial relationships that could be construed as a potential conflict of interest.

Copyright $\odot 2017$ Shah, Rehman, Akhtar, Daur, Nawaz, Ahmad, Rana, Atif, Yang and Chung. This is an open-access article distributed under the terms of the Creative Commons Attribution License (CC BY). The use, distribution or reproduction in other forums is permitted, provided the original author(s) or licensor are credited and that the original publication in this journal is cited, in accordance with accepted academic practice. No use, distribution or reproduction is permitted which does not comply with these terms. 